\title{
Non-destructive Analyses of 16th Century Printed Book "Osorio" with the Colorful Fore-edge Miniatures
}

\author{
Igor Lukačević, ${ }^{a, *}$ Ivona Ergotić, ${ }^{a}$ and Marina Vinaj ${ }^{b}$ \\ ${ }^{a}$ Department of Physics, University J. J. Strossmayer, Trg Ljudevita Gaja 6, 31000 Osijek, Croatia \\ ${ }^{\mathrm{b}}$ Museum of Slavonija, Trg Svetog Trojstva 6, 31000 Osijek, Croatia
}

RECEIVED DECEMBER 9, 2011; REVISED DECEMBER 10, 2012; ACCEPTED MAY 16, 2013

\begin{abstract}
In our study we are trying to illuminate the palette used by the artist who decorated the fore-edge of the Middle Age printed book description of the military campaign of the Spanish king Emanuel Hieronymus Osorio and try to give a temporal boundary on the moment of their creation. Our experiments show that a pigment palette is a common one for the period between 16th and 19th century. Several pigments were identified, like vermilion and minium, white lead and massicot. Further, we identified the ink used for the book cover inscriptions. Three complementary, non-invasive spectroscopic techniques were used: micro-Raman spectroscopy, PIXE spectroscopy and UV-VIS FORS spectroscopy. The challenges which occurred during the study are presented, such as the positioning of the book underneath the microscope or even the fiber optic probe holder, the roughness of the fore-edge surface and the thinness of the color layers.(doi: 10.5562/cca2040)
\end{abstract}

Keywords: medieval pigments; non-destructive analyses; Raman spectroscopy; PIXE spectroscopy; UVVIS FORS spectroscopy

\section{INTRODUCTION}

Croatia had possessed books continuously since the Middle Age. However, its medieval books seem to have been relocated forever. Many of the finest books used in medieval Croatia were originally brought from other countries. On a certain level, Croatia is curiously bare of medieval books: Croatian libraries exhibit often what are little more than fragments of salvage. ${ }^{1}$

In the fundus of the Department of printed books in the Museum of Slavonija in Osijek, Croatia, the library of Prandau-Normann family stands out by its worth both in quantity and historical significance. ${ }^{2}$ Almost 9000 books were brought to the Museum from their county chateau in Valpovo by the act of the Croatian Commission for the gathering and preservation of cultural goods (KOMZA). Their family library is an unavoidable fund for studying the cultural history of Slavonija, and the spring of numerous social studies, for it testifies about the fields of interest, social developments and activities of its owners, and its content is equivalent to the contents

\footnotetext{
i Slavonija is the eastern region of Croatia, bounded by the rivers of Drava, from the north, Sava, from the south, and Danube, from the east.
}

of the collections from other castles in Croatia and Central Europe.

In the early printed books many characteristics of the manuscripts remained. They were decorated, for the richer or more demanding owners, in a manner of manuscripts in many ways: in the text, places are left during the printing for the later hand made initials, illustrations are made by the woodcut and etching techniques, and the binding is followed by the rich decoration of the covers. One of the most beautiful examples of the 16th century Prandau-Normann collection is the description of the military campaign of the Spanish king Emanuel Hieronymus Osorio - Hieronymi Osorii Lvsitani Silvensis in Algarbiis episcopi..., ${ }^{\text {ii }}$ printed in the printing house of Arnold Birckmann, one of the three most famous Middle Age printers in Köln. The binding of the book is covered with brown leather and decorated with what on sight seems to be a golden oval medallion with an oriental motif. "Osorio" is decorated with seven foreedge miniatures, which were the centerpoint of our research: two on the upper and lower fore-edges and three on the side fore-edge. The sizes of miniatures are about $5 \times 4 \mathrm{~cm}$ and their author utilized several different

\footnotetext{
ii We will from now on refer to the book as "Osorio".
}

\footnotetext{
* Author to whom correspondence should be addressed. (E-mail: ilukacevic@fizika.unios.hr)
} 
(a)

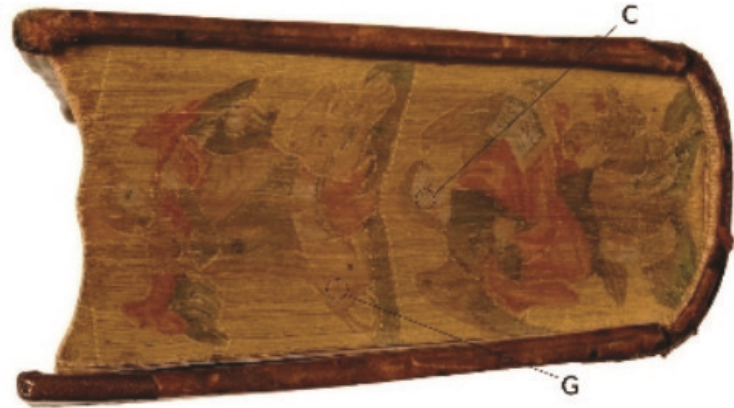

(b)

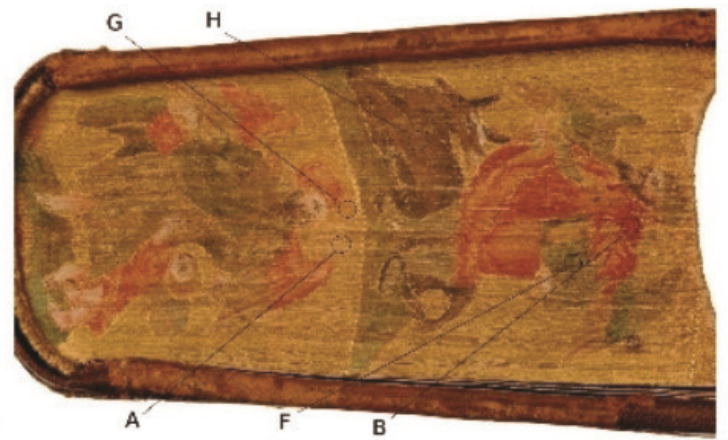

(c)

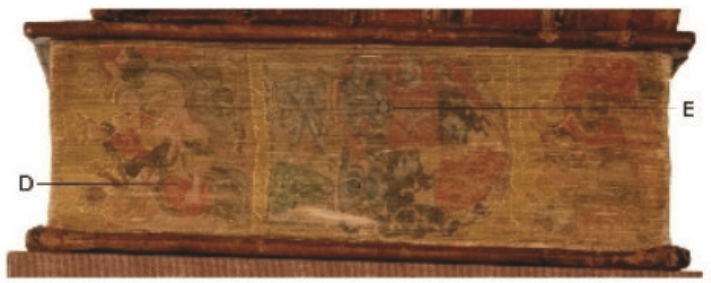

Figure 1. Miniatures on the upper (a), lower (b) and side of the fore-edge (c). Black circles and labels denote the areas which were used in the experiments: A - gold, B - red, $\mathrm{C}$ - pink, D - dark blue, E - light blue, F - green, $\mathrm{G}$ - yellow, $\mathrm{H}-$ brown.

colors: red, green, light blue, dark blue, yellow, pink and brown. They are all placed on a what appears to be a gilded fore-edge. The miniatures represent (two upper, two lower and three on the side, respectively): the four Evangelists, the Adoration of the Magi, an aristocratic coat of arms of an unknown origin and the Birth of Jesus (Figure 1). The inner side of the book cover is filled with the hand written notes of, now, light brownish color.

The path of "Osorio" from its printing table in Köln to the library of Prandau-Normann county is still under heavy fog. A decryption of the coat of arms, found on the fore-edge of the book, could possibly pinpoint to the one of the locations through which this book passed. There is little doubt that it is connected with the location of making of the miniatures. All miniatures appear to form a coherent set of decorations, which could mean that they were all made at the same time. But when were these miniatures made: not long after the printing or by the artist hired by one of its later owners? And which pigments did their author use? Some pigments were not so easily available or were expensive. Knowing which pigments were used could give some conclusions on the financial status of the owner client. On the other hand, some pigments were not used until certain time, which could point to the lower limit of the making of the miniatures. ${ }^{3}$

Further, similar questions can be raised concerning the ink used for the hand written inscriptions on the book cover. Most frequently used medieval ink, iron gall ink, was already studied experimentally, using both PIXE (particle induced X-ray emission) ${ }^{4}$ and $\operatorname{Raman}^{5}$ spectroscopy. The presence of elements and traditional techniques for making them were analyzed. Previous Raman study provides us a reference Raman spectrum for comparison. Our study should confirm that it is indeed the iron gall ink, which would set the possible boundaries on the time of making of inscriptions.

Spectroscopy is by now a well known method for studying the work of art. Recent developments (and demands of the owners of the artifacts) are bringing in front only the non-invasive (or non-destructive) spectroscopic methods in view. ${ }^{4,5}$ Most recent advances demand the use of non-invasive portable spectroscopic analyses. ${ }^{6}$ The subject of our research was in a condition under which it could be transported from the museum to the laboratories, without risking damage to the artifact. On the other hand, we were most of the time concerned with the outside of the book and, thus, did not have to open it frequently.

The book was previously under restoration, but with no significant effect to the study of pigments used in the coloration of the fore-edge.

\section{EXPERIMENTAL DETAILS}

\section{Samples}

We were met by a substantial positioning challenge, concerning the placement of the book in front of microscope during the Raman experiment or output ion beam in the PIXE experiment. First, when the inside of cover was studied, the cover of the book had to be held static, which was much easier to do during the Raman experiment (Figure 2(a)), since the book could be placed horizontally under the objective of microscope, than during the PIXE measurements, when the book had to be placed vertically (Figure 2(b)). Second, the miniatures are placed on the fore-edge, which does not have a smooth surface, for the binded pages do not all have the same width. Because of this, the scattering volume during the Raman experiment contained not just the wanted sample, but also the air and, more importantly, much of the underlying paper. Third, as the distance between the 
(a)

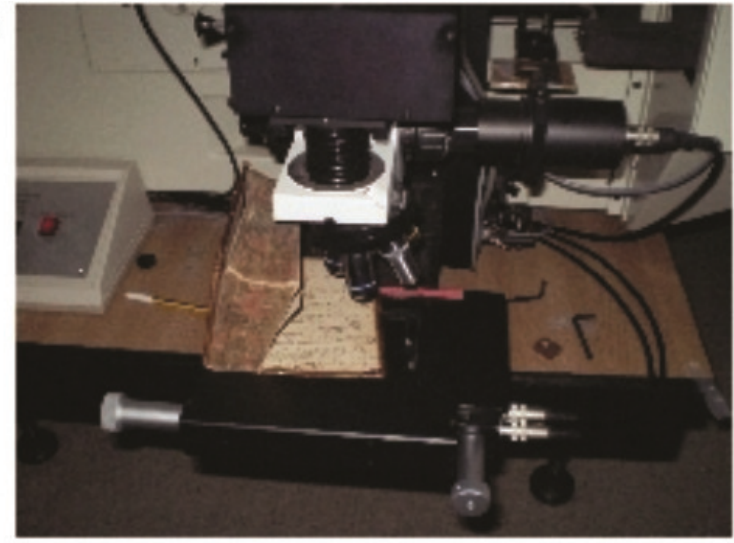

(b)

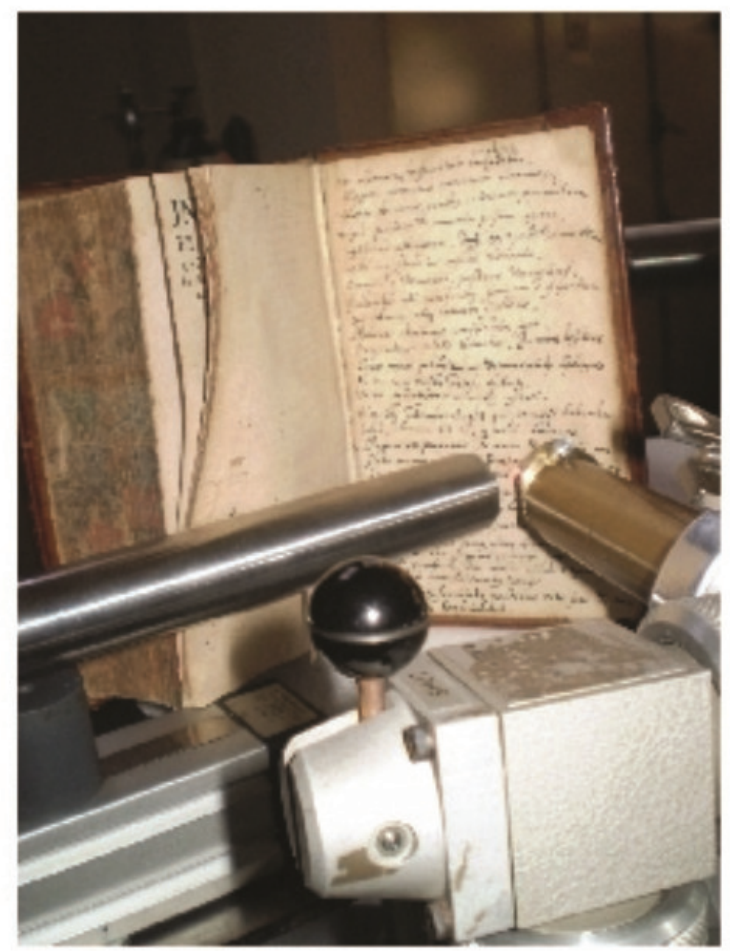

Figure 2. Positioning setup of the book cover during the Raman (a) and PIXE (b) experiments.

objective and the stage of a microscope was much smaller than the hight or the width of the book, the stage had to be screwed off, and the support of the book had to be improvised underneath by a table and other firm objects.

\section{Techniques}

In our study we used three different non-destructive spectroscopic methods. For the qualitative assessment of pigments, used in the creation of fore-edge miniatures, we used fiber optics UV-VIS reflection spectroscopy (UV-VIS FORS, ultra-violet and visible fiber optic reflection spectroscopy). We have decided to use FORS method because it is known that it can effectively complement Raman spectroscopy as far as the identification of pure and not too strongly absorbing pigments is involved, while, in the same time, it is important to have in mind that it is less useful when mixtures of pigments are encountered, ${ }^{5,7}$ and that it enables a nondestructive identification of pigments only when reference spectra are known. For reflection spectroscopy we utilized USB2000 UV-VIS spectrometer from Ocean Optics with a detector range 200-1100 nm. External light source was a tungsten halogen light bulb $(6.5 \mathrm{~W}$ power output). For signal acquisition we used the fiber optic probe, with or without the reflection probe holder, in a diffuse mode of reflectance (at an angle of $45^{\circ}$ with respect to the surface of the fore-edge), as the surface of the fore-edge is not flat and smooth, but convex in shape (the side fore-edge) and rough. This proved to be the main problem in gathering the reflectance spectra of the colorized areas in the miniatures, along with a inhomogeneity of the paint layers on the fore-edge. Selecting a smaller number of pages, which on their foreedge contain the desired colorized area, and of the width approximately equal to the diameter of the outgoing optic fiber beam, as to obtain a more or less flat surface, gave the same spectra.

For the qualitative analyses of the pigments we used two complementary spectroscopic techniques: PIXE and Raman microscopy. With Raman spectroscopy we were able to find out the molecular composition and the nature and the arrangement of chemical bonds in the material, while with PIXE we could find out the elemental composition of samples. It has to be stressed out that both these spectroscopic methods were available to us for a limited time only (several hours). Because of that, in most cases, only one sample of each studied area could have been investigated by these two spectroscopic methods, which no doubt has a negative impact on the quality of the results.

On-site micro-Raman spectroscopy was performed with Horiba Jobin-Yvon T64000 system using an $\mathrm{Ar}^{+}$ $514.5 \mathrm{~nm}$ laser excitation, with an output power of $20 \mathrm{~mW}$ and with attenuation filter of $0.3 \times$. The on sample laser power was, thus, about $3 \mathrm{~mW}$. This excitation (the only one available) proved in turn to be the main drawback of our Raman experiments, since it caused a significant fluorescence from the samples which overshadowed many of the Raman bands. The spectral resolution was about $3 \mathrm{~cm}^{-1}$. Total accumulation times were 1-2.5 minutes. The CCD detector $(1024 \times 256$ pixels $)$ was cooled by liquid nitrogen down to $140 \mathrm{~K}$. All the pigments' Raman bands were compared to the bands from the database made by Bell, Clark and Gibbs. ${ }^{8}$

During the PIXE analyses, samples were exposed to the $2 \mathrm{MeV}$ proton beam (effective energy was 1.7 $\mathrm{MeV}$ ) on a line with an external beam. Proton currents were as low as $1 \mathrm{nA}$, in order to avoid any possibilities 


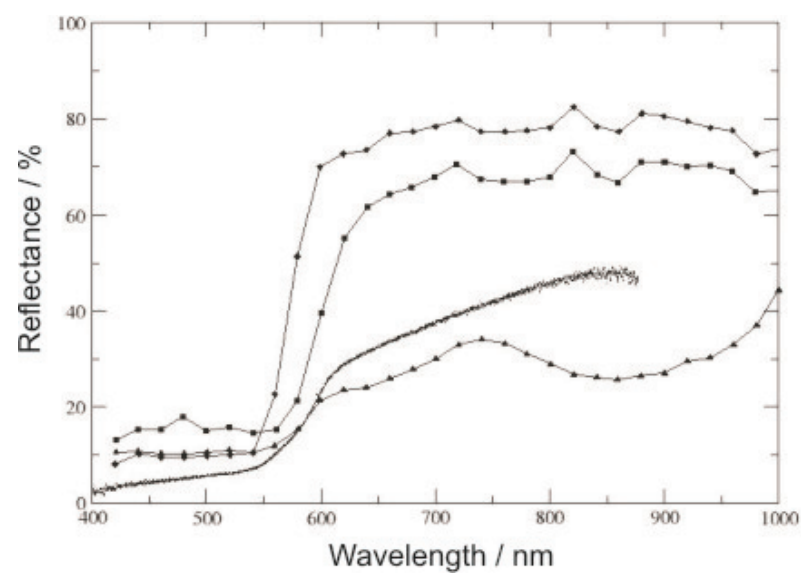

Figure 3. UV-VIS FORS spectrum of the red pigment (circles), compared to the FORS spectra of three common medieval pigments: vermilion (squares), minium (diamonds) and red earth (triangles).

of damaging the samples. As a X-ray detector we used Roentec $\mathrm{Si}(\mathrm{Li})$ detector with $80 \mathrm{~mm}^{2}$ of active surface, at a distance of about $20 \mathrm{~mm}$ from the samples, in order to increase the sensitivity. This kind of detector allowed us to analyze the elements heavier than Al. The beam spot had a diameter of about $1 \mathrm{~mm}$, and the position of the beam corresponds to the laser indicator position. The exact placement of the book was achieved manually and the position of the book was maintained by its own stability on the platform in front of the proton beam. All PIXE spectra show the presence of $\mathrm{Si}, \mathrm{S}$ and $\mathrm{Ca}$, which can be contributed to the paper, and Ar, which can be contributed to the air. Elemental analyses was done in comparison with X-ray line energies from Ref. 9.

All measurements were non-destructive and no visible damage was made to the samples during the exposure times to the laser or to the proton beam.

\section{RESULTS AND DISCUSSION}

\section{UV-VIS FORS Measurements}

UV-VIS reflection spectra of the colorized parts of the miniatures presented on the fore-edge revealed scarce informations, even qualitatively. Except for the red color, other colored areas could be distinguished between each other only by subtle differences. The reflection spectrum of red pigment can be compared with those of other commonly used medieval pigments (Figure 3): vermilion $(\mathrm{HgS})$, minium $\left(\mathrm{Pb}_{3} \mathrm{O}_{4}\right)$ and red ochre $\left(\mathrm{Fe}_{2} \mathrm{O}_{3}+\right.$ clay+silica). ${ }^{10}$ No decisive conclusions can be given on the basis of the reflection spectrum. The sharp incline between 550 and $600 \mathrm{~nm}$ resembles the ones for vermilion and minium, but the overall reflectance is lower. The reasons for this are very thin layers of paint, which were probably worn out through the years, the convex shape of the side fore-edge and the roughness of the fore-edge surface, since it consists of the book pages' sides of variable lengths. Thus, the low reflectance of the FORS spectrum is mainly due to the underlying paper and is influenced by the inability to sufficiently reduce the separation between the fore-edge and fiberoptic head.

\section{PIXE Measurements}

Gilt and Cover

Our first PIXE measurement confirmed that the gilded fore-edge of "Osorio" was indeed made using gold particles and ruled out the gold substitutions, like tin sulfide $\mathrm{SnS}_{2}$ (mosaic gold, aurum musicum or ormolu) and purpurinus, which are known to be used since 14th century (Figure 4(a)). The presence of gold was also found on the front cover of the book. As mentioned above, free hand inscriptions are present on the inside of the back cover (and the front first page). A strong presence of iron can be seen in the PIXE spectrum, suggesting the usage of the iron gall ink, a common ink since the late Middle Age (Figure 4(b)).

\section{Fore-edge}

The light presence of gold can be seen in the background of every colored area, as the depth of the proton scattering is larger than the thickness of the paint layers. Similarly, iron was detected in each studied sample. It could be a remnant of the printing procedure. Red pigmented areas show the presence of both lead and mercury (Figure $4(\mathrm{c})$ ). This can point to the usage of both vermilion ( $\mathrm{HgS})$ and red lead $\left(\mathrm{Pb}_{3} \mathrm{O}_{4}\right.$, minium) pigments. Pink color (skin) was usually obtained by mixing the red and white pigments. Pink areas show the presence of lead, and none of mercury, which means that the author used only minium as a pigment for producing the pink color, and left out the vermilion (Figure 4(d)). There could be two possible reasons for this: vermilion gives a more orangish and minium more a dull red color, and was, thus, more appropriate for obtaining the pink color, and/or minium was more available (maybe even financially) to the author at that time. The presence of lead could, also, indicate the usage of white lead $\left(2 \mathrm{PbCO}_{3} \cdot \mathrm{Pb}(\mathrm{OH})_{2}\right)$ for mixing with the red pigment. Not surprisingly, dark blue area shows the presence of copper, as most of the medieval blue pigments (before 18th century) contained copper: azurite, Egyptian blue, lazurite and posnjakite (Figure 4(e)). But the presence of lead and mercury cannot be easily explained based only on PIXE data. Light blue colored sample is elementally very similar to the dark blue one (Figure 4(f)). Except that in this case, one could explain the presence of lead that it originates from lead white, used by the author, to obtain the light blue color from the mixture of 

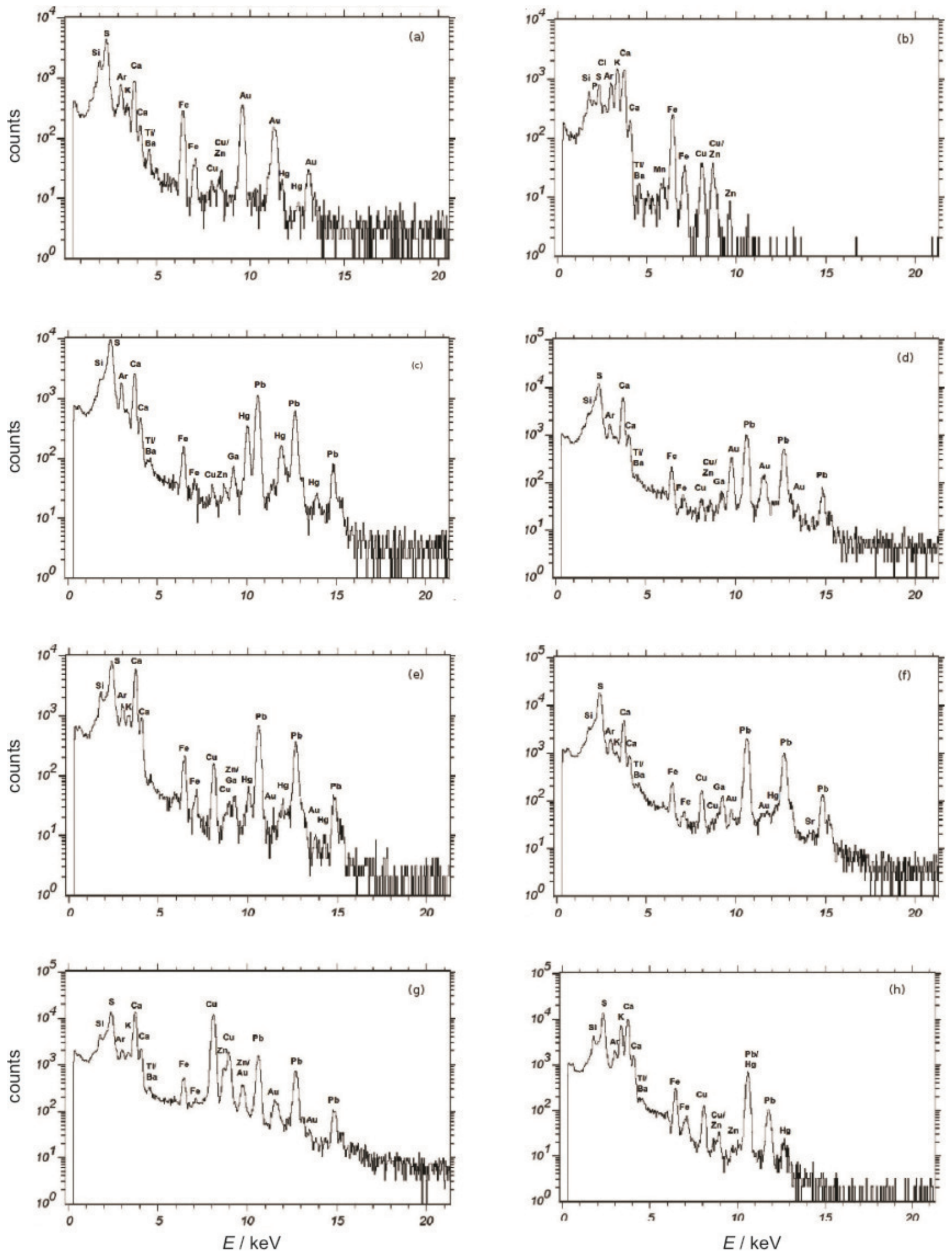

Figure 4. PIXE spectra of: gold (a), ink (b), red (c), pink (d), dark blue (e), light blue (f), green (g) and yellow (h) areas on the fore-edge or the cover of the book. The presence of $\mathrm{Si}, \mathrm{S}$ and $\mathrm{Ca}$ is contributed to the paper, and $\mathrm{Ar}$ to the air. 
Table 1. Artists' pigment palette found in the fore-edge areas as designated on Fig. 1, determined on the basis of UV-VIS FORS, PIXE and Raman spectroscopies. UV-VIS FORS spectra revealed only the red pigments, while many of the Raman spectra were covered with strong fluorescence. A detectable part of the palette consists of the pigments used in the Middle Age and up to 19th century

\begin{tabular}{|c|c|c|c|}
\hline Area & UV-VIS FORS & PIXE & Raman \\
\hline A & & gold & \\
\hline B & vermilion or minium & vermilion and minium & vermilion and minium \\
\hline $\mathrm{C}$ & & minium and white lead & minium and white lead \\
\hline $\mathrm{D}$ & & any copper blue pigment & any copper blue pigment \\
\hline $\mathrm{E}$ & & any copper blue pigment and lead white & any copper blue pigment \\
\hline $\mathrm{F}$ & & $\begin{array}{l}\text { malachite or verdigris or a mixture of copper } \\
\text { blue pigment and massicot }\end{array}$ & \\
\hline $\mathrm{G}$ & & massicot & \\
\hline $\mathrm{H}$ & & & minium \\
\hline
\end{tabular}

dark blue and white pigments. Green colored area PIXE spectrum contains, among others, copper and lead (Figure $4(\mathrm{~g})$ ). This could lead to the following conclusions: either the author used one of the green pigments (containing copper), available in medieval times, like malachite or verdigris, but in this case the presence of lead is not obvious, or the author used a mixture of blue (containing copper) and yellow (containing lead or even possibly iron) pigments to produce the green color. The presence of zinc remains unexplained. Lead is predominant in the yellow colored areas (Figure 4(h)), possibly originating from the usage of massicot $(\mathrm{PbO})$. Identified pigments are summarized in Table 1.

\section{Raman Measurements}

Any assumptions raised up by the results of the PIXE experiments, should have been resolved by Raman spectroscopy. The occurrence of fluorescence, caused by the $\mathrm{Ar}^{+}$laser, used in Raman spectroscopy experiments and present during every irradiation of the samples, covered most of the Raman bands coming from the pigments.
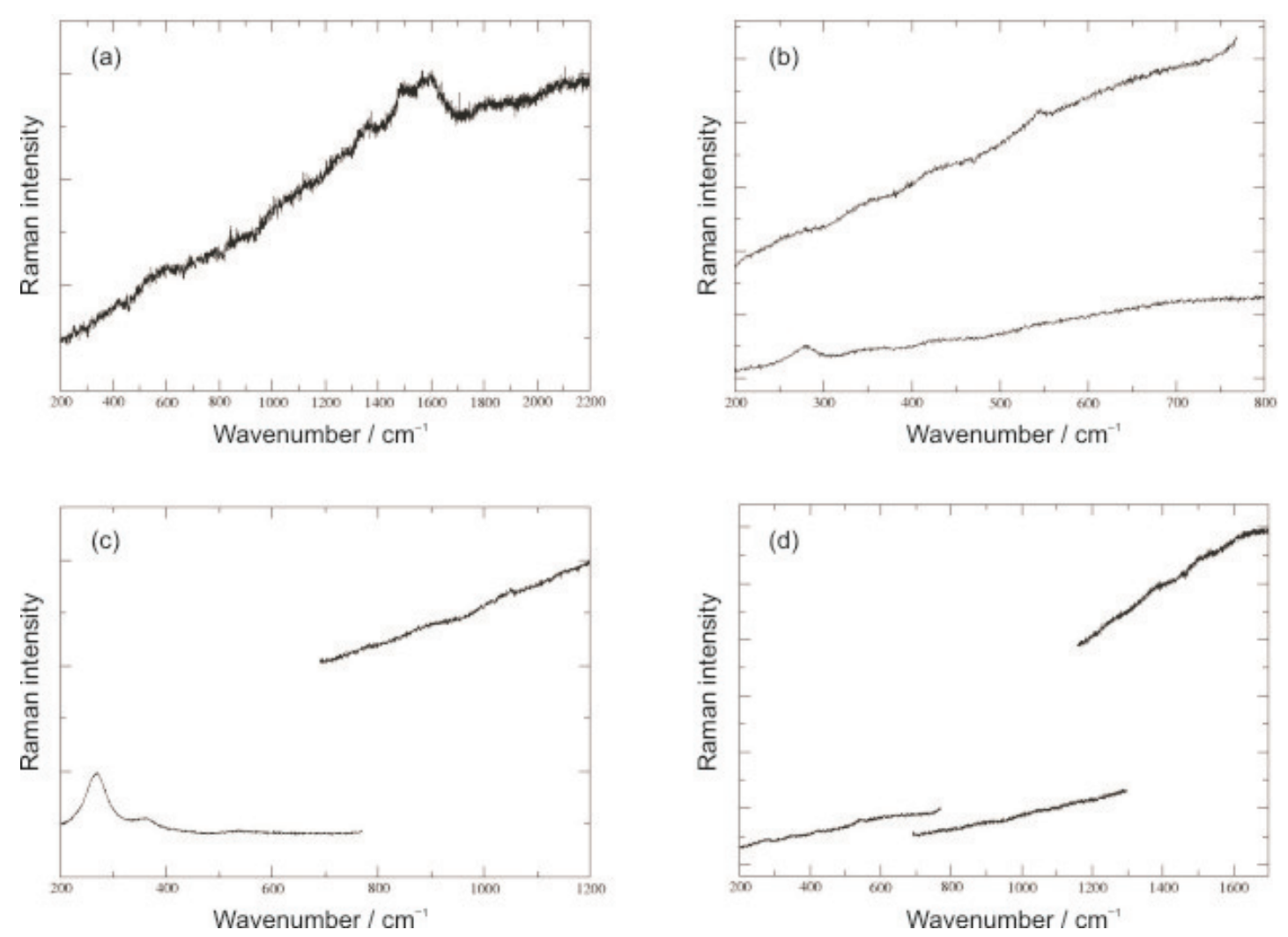

Figure 5. Raman spectra of: ink (a), red (b), pink (c) and brown (d) areas on the fore-edge or the cover of the book. 
Roughness of the fore-edge and the thinness of the colored layers on it certainly contributed also to the weak signals, as the Raman scattering volume did not contain only the pigment minerals, but also the underlaying paper and a certain amount of air. Each Raman spectrum contained the same bands between 2000 and 4000 $\mathrm{cm}^{-1}$, and we have, thus, assigned them to the underlying paper. ${ }^{11-13}$ Bands in the region between 3000 and $4000 \mathrm{~cm}^{-1}$ belong to the $\mathrm{O}-\mathrm{H}$ stretching motions, while those between 2000 and $3000 \mathrm{~cm}^{-1}$ to the $\mathrm{C}-\mathrm{H}$ stretching motions of cellulose. ${ }^{12}$

\section{Gilt and Cover}

Gilded fore-edge of the book has no first order Raman spectrum. The notes on the inside of cover were most probably made with iron gall ink (Figure 5(a)). Our Raman bands, at about 410, a broad feature between 500 and 600, 1350, 1480 and $1600 \mathrm{~cm}^{-1}$, coincide well with the bands obtained by Lee et al., ${ }^{14}$ who compared the Raman spectra of the historical iron gall inks with the prepared ones, according to the traditional recipes.

\section{Fore-edge}

Raman spectrum of red colored area shows two discernible peaks, obtained from two different measurements on the same spot: one at $280 \mathrm{~cm}^{-1}$ and the other at $545 \mathrm{~cm}^{-1}$ (Figure 5(b)). The first one is attributed to vermilion and the second one to minium. This result would confirm our predictions, based on the results of PIXE spectroscopy, that the author used both vermilion and minium as a mixture for the red color. In the pink colored areas our Raman measurements display a clear peak around $150 \mathrm{~cm}^{-1}$, which is very close to the medium peak of minium at $149 \mathrm{~cm}^{-1}$, and a smaller one at around $360 \mathrm{~cm}^{-1}$ (Figure 5(c)). This second peak is hard to attribute. Three different red pigments have a peak in the proximity of $360 \mathrm{~cm}^{-1}$, but two of them can be ruled out, realgars' $\left(\mathrm{As}_{4} \mathrm{~S}_{4}\right)$ at $354 \mathrm{~cm}^{-1}$ and vermilions' $(\mathrm{HgS})$ at $343 \mathrm{~cm}^{-1}$, based on the absence of As and $\mathrm{Hg}$ in the PIXE spectrum. There is a small possibility that it belongs to miniums' peak at $340 \mathrm{~cm}^{-1}$. A hardly discernible peak, almost completely covered by the fluorescence, at around $1055 \mathrm{~cm}^{-1}$ can be seen, also. It is very close to the very strong band of lead white at $1050 \mathrm{~cm}^{-1}$. This result is in accordance with PIXE results. One color we did omit during the PIXE experiments: brown, used for the skin of the magi Balthazar and the cows' fur. Only one Raman band at about $545 \mathrm{~cm}^{-1}$ (Fig. 5(d)) can be recognized here. It is closest to the strong $548 \mathrm{~cm}^{-1}$ band of minium, which, if mixed with a green pigment (or a mixture of blue and yellow), would produce a brown color.

Identified pigments are summarized in Table 1.

\section{CONCLUSION}

We have used three different and complementary spectroscopic methods in order to try to answer the questions about the decorations on the 16th century printed book "Osorio". The complementarity of these methods was one of the key issues which enabled us to reach these answers.

The main goal was to identify the pigments used in the coloration of the miniatures placed on the foreedge of the book. As far as the pigments, which we were able to identify, are concerned, we can bring out the conclusion that all miniatures were made at the same time and, presumably, by the same author. The pigment palette used in the creation of the miniatures consists of the pigments which were available and commonly used in 16th and up to 19th century. This fact leads us to the conclusion that the miniatures were most probably created before 19th century. The miniatures are probably a work of an artist employed by one of the previous owners of the book, while it was in their possession. We could not give a definite answer whether all the miniatures were made by a single artist or more of them, because of the time limitations of our experiments, during which we could not record the spectra of all the occurrences of the observed colors. Because of the beauty of the work, and undoubtedly a huge amount of time needed to make such decorations, we presume that "Osorio" had a special meaning to the one of its previous owners. This conclusion can, also, be supported by the fact that its fore-edge was gilded using gold particles, and not one of the gold substitutes.

Concerning the handwritten inscriptions on the inside of book cover, we have managed to identify the ink which was used as the iron gall ink, a common medieval ink. Both PIXE and Raman spectra confirm our conclusion.

Fluorescence, coming from the usage of the $\mathrm{Ar}^{+}$ laser, was the main negative factor during the Raman experiments. For some of the pigments, it was so large that it covered all of the pigments spectral lines. For these pigments, we could only bring assumptions based on the PIXE results. Fluorescence has, thus, prevented us to obtain the pigment identification with certainty for several colors. We presume that using the laser with the larger wavelength would not induce such fluorescence and, consequently, more Raman lines would be visible, making the pigment identification more definite. Furthermore, the layers of colors on the fore-edge of the book are very thin (probably due to their weariness), while the fore-edge, itself, is not a smooth surface. All these facts significantly influenced the quality of the obtained Raman spectra, because of the scattering from the underlying paper, which again certainly contributed to the occurrence of the fluorescence.

In all, with this study, we have shown that studying the decorations located on the fore-edge of the book 
can present a significant challenge to the spectroscopists. Especially when one has no fiber optics enhanced spectroscopic equipment at hand.

Acknowledgements. We would like the thank Dr. Davor Kirin and Lara Mikac from the Laboratory for the Molecular Physics at the Rudjer Bošković Institute, for giving us the opportunity and help with the micro-Raman spectrometer. Also, we would like the thank Dr. Milko Jakšić, Dr. Tonči Tadić, Dr. Richard Smith and Veljko Grilj, for giving us the opportunity and help with the 1.0 MV Tandetron accelerator stationed in the Laboratory for Ion Beam Interactions at the Rudjer Bošković Institute.

\section{REFERENCES}

1. C. de Hamel, Illuminated manuscripts in Croatia, in Croatia Aspects of art, architecture and cultural heritage, Frances Lincoln Limited, London, 2009.
2. M. Vinaj, Tiskopisi XVI. stoljeća iz riznice Muzeja Slavonije u Osijeku, Muzej Slavonije, Osijek, 2007.

3. http://www.webexhibits.org/pigments/intro/history.html

4. M. Budnar, J. Simčič, Z. Rupnik, M. Uršič, P. Pelicon, J. Kolar, and M. Strlič, Nucl. Instr. and Meth. B 219-220 (2004) 41-47.

5. H. G. M. Edwards, and J. M. Chalmers, Raman spectroscopy in archeology and art history, Royal Society of Chemistry, Cambridge, 2005.

6. E. Ciliberto, and G. Spoto, Modern analytical methods in art and archeology, John Wiley \& Sons, New York, 2000, p. 321.

7. P. Vandenabeele, J. Tate, and L. Moens, Anal. Bioanal. Chem. 387 (2007) 813-819.

8. I. M. Bell, R. J. H. Clark, and P. J. Gibbs, Spectrochim. Acta A.M. 53 (1997) 2159-2179.

9. http://xdb.lbl.gov/Section1/Sec_1-2.html

10. http://codexsinaiticus.org/en/project/conservation_msi.aspx

11. U. P. Agarwal, Planta 224 (2006) 1141-1153.

12. R. H. Atalla, and D. L. Vanderhart, IPC Technical Paper Series 306 (1988) 1-20.

13. http://www.tappi.org/content/events/08nano/papers/08nan05.pdf

14. A. S. Lee, P. J. Mahon, and D. C. Creagh, Vib. Spectros. 41 (2006) 170-175. 